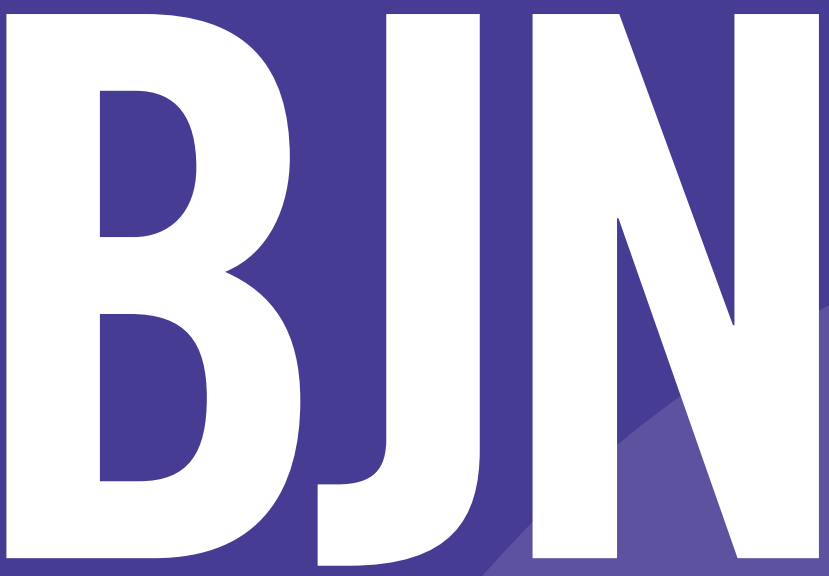

\title{
BRITISH JOURNAL OF NUTRITION
}

Volume: 107

Number: 3

14 February 2012

An International Journal

of Nutritional Science 


\title{
British Journal of Nutrition \\ An International Journal of Nutritional Science \\ Volume 107, 2012 ISSN: 0007-1145
}

\begin{abstract}
Aims and Scope
The British Journal of Nutrition is an international, peer-reviewed journal publishing original papers, review articles, short communications and technical notes on human and clinical nutrition, animal nutrition and basic science as applied to nutrition. Correspondence is encouraged in a Nutrition Discussion Forum. The Journal recognizes the multidisciplinary nature of nutritional science and encourages the submission of material from all of the specialities involved in research and clinical practice. The Journal also publishes supplements on topics of particular interest.
\end{abstract}

The British Journal of Nutrition is published twice monthly by Cambridge University Press on behalf of The Nutrition Society.

The British Journal of Nutrition is available online to subscribers at journals.cambridge.org/bjn Tables of contents and abstracts are available free at the same website.

\section{Editor-in-Chief}

P C Calder, School of Medicine, University of Southampton, Southampton, UK

\section{Deputy Editors}

F Bellisle, INRA, University of Paris, Bobigny, France

D R Jacobs Jr, School of Public Health, University of Minnesota, Minneapolis, MN, USA

R J Wallace, Gut Health Programme, Rowett Institute of Nutrition and Health, University of Aberdeen, Aberdeen, UK S J Whiting, College of Pharmacy and Nutrition, University of Saskatchewan, Saskatoon, Sask., Canada

\section{Reviews Editors}

P Aggett, School of Medicine and Health, Lancaster University, Lancaster, UK

D J Millward, Faculty of Health and Medical Sciences, University of Surrey, UK

Systematic Reviews Editor

M Makrides, Women's and Children's Health Research Institute and University of Adelaide, Adelaide, Australia

\section{Supplements Editor}

J Woodside, Nutrition and Metabolism Group, Centre for Public Health, Queen's University, Belfast, UK

\section{Editorial Board}

J J B Anderson, Chapel Hill, NC, USA
Y Bao, Norwich, UK
J H Beattie, Aberdeen, UK
G Bell, Stirling, UK
M Blaut, Bergholz-Rehbrücke, Germany
T Bohn, Belvaux, Luxembourg
J T Brenna, Ithaca, NY, USA
S Brix Pedersen, Lyngby, Denmark
G C Burdge, Southampton, UK
A E Buyken, Dortmund, Germany
J Buyse, Leuven, Belgium
K D Cashman, Cork, Ireland
R S Chapkin, College Station, TX, USA
M S Choi, Daegu, Korea
A Collins, Oslo, Norway
S J Duthie, Aberdeen, UK
U Ekelund, Cambridge, UK
A Esmaillzadeh, Isfahan, Iran
B A Fielding, Oxford, UK
J L Firkins, Columbus, OH, USA
J K Friel, Winnipeg, MB, Canada
M Fukushima, Obihiro City, Japan
S Garnett, Sydney, Australia
B A Griffin, Surrey, UK
J C G Halford, Liverpool, UK
W Hendriks, Wageningen, The Netherlands
E Herrera, Madrid, Spain

L T Ho, Taipei, Taiwan

D J Hoffman, New Brunswick, NJ, USA

G Janssens, Merelbeke, Belgium

E J Johnson, Boston, MA, USA

S J Kaushik, Saint Pée-sur-Nivelle, France

D S Kelley, Davis, Ca., USA

C W C Kendall, Toronto, Ont., Canada

J P Lallès, Rennes, France

A Laviano, Rome, Italy

H J Lightowler, Oxford, UK

A M López-Sobaler, Madrid, Spain

J A Lovegrove, Reading, UK

S R Lynch, Grafton, VA, USA

R D Mattes, West Lafayette, IN, USA

C Mayer, Aberdeen, UK

S McCann, Buffalo, NY, USA

J P McClung, Natick, MA, USA

N M McKeown, Boston, MA, USA

S McMullen, Nottingham, UK

D McMurray, College Station, TX, USA

S McNaughton, Burwood, Australia

J G Mercer, Aberdeen, UK

A M Minihane, Norwich, UK

T A Mori, Perth, Australia

H Mukhtar, Madison, WI, USA

M Murphy, Reus, Spain

P Nestel, Southampton, UK
U Nöthlings, Kiel, Germany

C M Nyachoti, Winnipeg, MB, Canada

M C Ocké, Bilthoven, The Netherlands

A Palou, Palma de Mallorca, Spain

P Palozza, Rome, Italy

J H Y Park, Chuncheon, Korea

E Perissinotto, Padova, Italy

C J Petry, Cambridge, UK

S Proctor, Edmonton, Alta., Canada

W D Rees, Aberdeen, UK

G Rimbach, Kiel, Germany

P Ritz, Angers, France

S M Robinson, Southampton, UK

E Ros, Barcelona, Spain

S Salminen, Turku, Finland

M B Schulze, Nuthetal, Germany

T Sheehy, Cork, Ireland

A J Sinclair, Geelong, Australia

C R Sirtori, Milan, Italy

A Sjödin, Copenhagen, Denmark

K S Swanson, Urbana, IL, USA

D Tomé, Paris, France

D Topping, Adelaide, Australia

F Visioli, Madrid, Spain

J H M de Vries, Wageningen, The Netherlands

M R Yeomans, Sussex, UK

\section{Publications Staff}

C Goodstein (Publications Manager), C Jackson (Deputy Publications Manager),

L Weeks, C T Hughes, D Owen and L King (Publications Officers)

The Nutrition Society has as its objective the advancement of the scientific study of nutrition and its applications to the maintenance of human and animal health.

Application of membership is invited from anyone whose work has contributed to the scientific knowledge of nutrition, whether such work has been in the laboratory, the field or the clinic, and whether experimental, clinical, agricultural or statistical in nature. There is also a student membership scheme with reduced subscriptions.

Particulars of The Nutrition Society and application forms for membership are available from The Nutrition Society, 10 Cambridge Court, 210 Shepherds Bush Road, London W6 7NJ, UK. Tel: +44 (0)20 7602 0228, Fax: +44 (0)20 7602 1756, Email: office@ nutsoc.org.uk 